\title{
In vitro efficacy of different growth media and crude plant extracts against mycelia growth of Phytophthora capsici
}

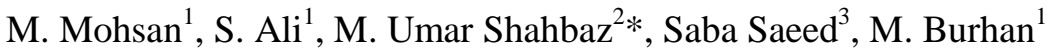 \\ ${ }^{1}$ Lower Fungi Lab, Plant Pathology Section, AARI, Faisalabad, Pakistan. ${ }^{2}$ Molecular Plant Pathology Lab, Institute of Plant Protection, Graduate School of \\ Chinese Academy of Agricultural Sciences (GSCAAS), Beijing 100081, China. ${ }^{3}$ Plant Virology Section, Plant Pathology Section, AARI, Faisalabad, \\ Pakistan.
}

\begin{tabular}{|c|c|}
\hline ARTICLE INFO & ABSTRACT \\
\hline $\begin{array}{l}\text { Article history: } \\
\text { Received on: } 14 / 02 / 2017 \\
\text { Accepted on: } 17 / 05 / 2017 \\
\text { Available online: } 14 / 08 / 2017\end{array}$ & $\begin{array}{l}\text { Different growth media; PARP (Pimaricin }+ \text { Ampicilin }+ \text { Rifampicin }+ \text { PCNB), Carrot Agar, Rye Agar and } \\
\text { V8 Juice Agar were evaluated against mycelial growth of Phytophthora capsici. During isolation PARP was } \\
\text { found the best medium as mean colony diameter of } 2.2 \mathrm{~cm} \text { was observed while no growth of P. capsici was } \\
\text { found on any other media. Plant extracts Calotropis gigantean (Akk), Cassia fistula (Amaltas), Nerium }\end{array}$ \\
\hline $\begin{array}{l}\text { Key words: } \\
\text { Cassia, Nerium, Parthenium, } \\
\text { Phytophthora, Pimaricin, } \\
\text { Oscimum. }\end{array}$ & $\begin{array}{l}\text { oleander (Kaner), Oscimum basilicum (Niazbo), Parthenium hysterophorus (Parthenium) and Azadirachta } \\
\text { indica (Neem) were assessed against mycelia growth of } P \text {. capsici in vitro. Parthenium hysterophorus totally } \\
\text { inhibited the growth of } P \text {. capsici, Nerium oleander and Oscimum basilicum also prove effective to some } \\
\text { extent. Although Azadirachta indica, Cassia fistula and Calotropis gigantea stimulated the growth of } P \text {. } \\
\text { capsici. }\end{array}$ \\
\hline
\end{tabular}

\section{INTRODUCTION}

Phytophthora capsici is an oomycete plant pathogen that causes blight and fruit rot of peppers and other important commercial crops. It was first reported by L. Leonian at a New Mexico Agricultural Research Station in Las Cruces in 1922 on a crop of chili peppers. Similarly, in 1967, a study by Satour and Butler found 45 species of cultivated plants and weeds that was susceptible to $P$. capsici. In Greek, $P$. capsici means "plant destroyer of capsicums" [1]. $P$. capsici has a wide range of hosts including members of the Solanaceae and Cucurbitaceae family as well as Fabaceae. P. capsici produces microscopic, asexual spores called sporangia. Sporangia are nearly spherical to pyriform (pear shape), hyaline (colorless), papillate (pointed at the tip), caducous (spores fall from the colony) and have a long pedicel (stalk) attached to the base of the spore. In water, sporangia form and release several swimming spores called zoospores. Sporangia also germinate directly by producing

* Corresponding Author

Muhammad Umar Shahbaz, Molecular Plant Pathology Lab, Institute of

Plant Protection, Graduate School of Chinese Academy of Agricultural Sciences (GSCAAS) Beijing (Haidian) 100081, China.

Email: umar739@yahoo.com several germ tubes that begin new fungal colonies. $P$. capsici is heterothallic and has two mating types (A1 and A2). Both mating types are needed for the abundant production of sexual spores called oospores. Oospores are thick walled and form within a mother cell called the oogonium, which is red or orange in some types of media. Some species of Phytophthora are induced to form oospores when the mating type of another species is present. Sporangia are spread by splashing water from irrigation or rain. With moisture present, zoospores are formed and released. These zoospores swim for a few minutes to more than an hour before encysting. Environmental conditions such as water temperature, nutrition, $\mathrm{pH}$, and other factors determine the length of time zoospores continue to swim. The germ tube commonly penetrates the leaf through stomata's which are natural opening in the leaf epidermis. This pathogen grows well between $25^{\circ} \mathrm{C}$ to $30^{\circ} \mathrm{C}$ and optimum growth temperature is $28^{\circ} \mathrm{C}$. In recent years, natural plant products as environmentally safe option have received attention for controlling phyto-pathogenic diseases throughout the world. Therefore, considerable research to search for biocides that are environmentally safe and easily biodegradable have been carried out during last two decades [2, 3]. The chemical management of plant diseases have several drawbacks and is also environmentally hazardous. The use of natural products for the control of fungal diseases in plants is considered an interesting alternative to 
synthetic fungicide due to their negative impacts on the environment. In the hope to find such an alternative, the antifungal properties of several commonly available medicinal plants and some plant products were investigated and reported herewith. Among the natural fungicidal substances, garlic (Allium sativum) extract has been found active in various trials in vitro and to a less degree in vivo. However, little is known about the effectiveness on $P$. infestans. Bio-clean, an organic bactericide and fungicide, was derived from natural organic acids mixed with ascorbic acids and citrus extracts derivatives. It is an ingredient used to manufacture diverse finished products for food, cosmetics, pharmaceutical and agricultural industries. No inhibitory tests on $P$. infestans have ever been made. Scouring rush (Equisetum hyemale L.) is one kind of weed that is very common in California. Research has shown that scouring rush has inhibition effects on development of insects. Moreover, Citronella oil, which is $100 \%$ pure essential oil, has been used as repellent material for insects but no studies have been reported about its inhibition effects on $P$. infestans. Preliminary in vitro experiments conducted with several plant crude extracts showed that some of extracts could effectively control $P$. drechsleri. Plants such as Zataria multiflora, Pinus halepensis, Carum carvi [4], Cinnamomum zelanicum [5] and Xanthium strumarium [6] significantly suppressed the mycelial growth of P.drechesleri. Methanol and ethyl acetate extracts of yellow oleander (Thevetia peruviana) had a range of inhibitory effects on the mycellial growth of different strains of $P$. megakarya, the agent of black pod disease [7]. In vivo experiments using crude plant extract against Phytophthora blight of pepper caused by $P$. capsici showed that the severity of disease was reduced by cabbage, garlic and alfalfa extracts [8]. The objectives of the present study, as part of larger screening program, were to identify plant sources with anti-phytophthora activity, determine which plant parts have higher activity and to find the active fractions.

Lilly \& Barnett (1951) tested bean, carrot, maize meal and oatmeal extract agar, LBA, potato dextrose, potato glucose and water agar tested as culture media [9]. The most satisfactory was LBA, prepared from the standard Difco medium and used at $2.3 \%$ in water and this was employed in all experiments, unless otherwise stated. The objectives of the present study, as part of larger screening program, were to identify plant sources with antiphytophthora activity, determine which plant parts have higher activity and to find the active fractions.

\section{MATERIAL AND METHODS}

\subsection{Different media for $\boldsymbol{P}$. capsici growth}

There are different media which can be used for $P$. capsici growth. In this study we compared following four against P. capsici.

\subsubsection{Preparation of PARP medium}

The PARP medium was prepared by following procedure described by Kanwissher and Michael (1978)[10]. Corn meal agar (17 g) was added in 1 liter of distilled water and autoclaved at $121^{\circ} \mathrm{C}$ at 15 psi pressure for $20 \mathrm{~min}$. Then allow the media to cool down up to $45{ }^{\circ} \mathrm{C}$. Antibiotics were prepared in two small flasks. In one flask Pimaricin $0.4 \mathrm{~mL}$, Ampicillin $0.25 \mathrm{~g}$ and PCNB $5 \mathrm{~mL}$ were added and dissolved in $10 \mathrm{~mL}$ distilled water. In second flask Rifampicin0.01g, $1 \mathrm{~mL}$ DMSO and $10 \mathrm{~mL}$ distilled water were added. Now the mixtures of these two flasks were added in flask containing corn meal agar.

The flask was shaken vigorously to make the solution homogenous. PARP medium is sensitive to light because of presence of antibacterial and antifungal substances which become ineffective in the presence of light so the pouring was carried out in low light. After pouring into sterilized Petri plates, the medium was allowed to solidify and after that Petri plates containing medium were wrapped in newspaper and placed in incubator. The suspected Phytophthora spp. was isolated from infected chilies leaves.

The chilies leaves were cut into small pieces, immersed in $70 \%$ alcohol for $2 \mathrm{~min}$, rinsed twice with distilled water, dry by placing on autoclaved filter paper and transfer to Petri plates containing PARP medium under a septic condition.

\subsubsection{Preparation of Carrot Agar medium}

Carrots $(200 \mathrm{~g})$ were washed with tap water. Peeled and sliced them into small pieces. One liter water was added in the carrots and blending was carried out for 1-2 min. After blending the mixture was passed through double layer of muslin cloth. Then the filtrate was poured in a 2 lit flask and agar agar was added and autoclaving was carried out at $121^{\circ} \mathrm{C}$ at 15 psi pressure for $20 \mathrm{~min}$. After cooling the $1 \mathrm{cc}$ streptomycin was added in the mixture and was poured in Petri plates and allowed to solidify [11]. Isolation was carried out by the same procedure described earlier.

\subsubsection{Preparation of Rye Agar medium}

Rye seeds $(50 \mathrm{~g})$ were soaked in 1 lit of water for 24-36 hrs. After that seeds were separated from water. The seeds were then blended well and again add soaking water. Then passed this mixture through two layers of muslin cloth. Agar was added and autoclaving was carried out at $121^{\circ} \mathrm{C}$ at 15 psi pressure for $20 \mathrm{~min}$. After cooling, 1cc streptomycin was added in medium and poured in Petri plates and allowed it to solidify [12].

\subsubsection{Preparation of V8 juice agar}

V8 juice $(200 \mathrm{~mL})$ and 1 lit water were added in 2lit flask and stirred vigorously. Then $\mathrm{CaCO}_{3}(2 \mathrm{~g})$ and agar agar $(15 \mathrm{~g})$ was added and mixed. Autoclaving was carried out at $121{ }^{\circ} \mathrm{C}$ at $15 \mathrm{psi}$ pressure for $20 \mathrm{~min}$. After cooling the medium was poured in Petri plates and allowed to solidify. Isolation and sub culturing was carried out.

\subsection{Different plant extracts to study mycelial growth of P. capsici}

\subsubsection{Plant species}

Throughout the world there are many plants which are using for management of different plant diseases. Following six 
plant species were selected for study/ comparison against $P$. capsici. Aqueous extracts of these plant species were collected to evaluate for their efficacy against $P$. capsici.

$\begin{aligned} \text { i. } & \text { Parthenium (Parthenium hysterophorus) } \\ \text { ii. } & \text { Neem (Azadirachta indica) } \\ \text { iii. } & \text { Niazboo(Oscimum basilicum) } \\ \text { iv. } & \text { Kaner (Nerium oleander) } \\ \text { v. } & \text { Akk (Calotropis gigantea) } \\ \text { vi. } & \text { Amaltas (Cassia fistula) }\end{aligned}$

\subsubsection{Preparation of plant extracts}

Leaf parts of the plant samples were washed carefully. Then dried them by placing on the newspaper for one day. By using the weighing balance $25 \mathrm{~g}$ of each plant sample was taken. The samples were crushed one by one in a blender by adding $25 \mathrm{~g}$ of each sample in $75 \mathrm{~mL}$ water and aqueous solution was prepared [13]. All six plant extracts were prepared by following the same procedure. After crushing, the aqueous extracts were poured into six separate flasks. Then each extract was passed through double layer of muslin cloth. Moistened filter papers were folded into cone shape, placed it on the mouth of another empty flask and extract was poured onto it for filtration. This procedure was repeated for all plant extracts and obtained pure filtrate of all plant extracts. No autoclaving was carried out for plant extracts; they were mix with Potato Dextrose Agar just before pouring the media into Petri dishes.

\subsubsection{Preparation of Potato Dextrose Agar (PDA) medium}

Glucose and agar agar were dissolved in $500 \mathrm{~mL}$ sterilized water in a flask. Then starch was dissolved in $500 \mathrm{~mL}$ of distilled water in another flask. Both solutions were mixed together in a $1000 \mathrm{~mL}$ flask and 2cc streptomycin was added. The medium was autoclaved at $121^{\circ} \mathrm{C}$ temperature and $15 \mathrm{psi}$ pressure. After autoclaving it was cool down for some time.

\subsubsection{Mixing of PDA and plant extracts}

Required quantity of PDA was divided in 7 flasks 100 $\mathrm{mL}$ in each flask. With the help of a sterilized pipette $10 \mathrm{~mL}$ of each plant extract was added separately into the flasks containing molten and cooled $100 \mathrm{~mL}$ PDA and mixed thoroughly. This procedure was repeated for all plant extracts and all plant extracts were mixed in the medium.28 Petri dishes were taken, 4 replications were maintained for each plant extract treatment and the medium containing Amaltas extract was poured into 4 Petri plates $25 \mathrm{~mL}$ in each. Similarly, all the plant extracts were poured in Petri dishes and Petri dishes were labelled. Control was maintained without adding any extract to the medium.

\subsubsection{Inoculation}

After filling the Petri dishes, culture of $P$. capsici was taken and with the help of a sterilized cork-borer 5mm disks of fungal growth were cut. All this work was carried out under aseptic conditions in a laminar flow chamber. Petri dishes containing plant extracts plus PDA were taken and $5 \mathrm{~mm}$ disks were cut from the leading edges of mycelial growth of each Petri dish with a sterilized cork-borer. With the help of a sterilized needle, $5 \mathrm{~mm}$ disks from the culture plate were transferred to the medium containing plant extract one by one. Four dishes were kept as control without adding any plant extract and were inoculated as well. Petri dishes were labelled and wrapped in newspapers separately for each treatment. Petri dishes were incubated in an incubator at $22^{\circ} \mathrm{C}$ temperature.

\section{RESULTS AND DISCUSSIONS}

\subsection{Effect of media on $P$. capsici growth}

Mycelial growth of P.capsici during isolation on PARP medium was $2.2 \mathrm{~cm}$ after 3 days, $5.1 \mathrm{~cm}$ after 6 days and $7.6 \mathrm{~cm}$ after 9 days respectively, while no growth was recorded on other media like carrot agar, rye agar and V8 respectively. During isolation PARP was found most effective medium for mycelial growth of P.capsici. While on the other hand the remaining three media don't show any mycelial growth. During sub culturing a good mycelial growth was observed on all media, on PARP an average growth of $3.3 \mathrm{~cm}, 6 \mathrm{~cm}$ and $7.06 \mathrm{~cm}$ after 3,6 and 9 days was recorded respectively. On V8 medium an average growth of $3.8 \mathrm{~cm}, 5.9 \mathrm{~cm}$ and 8.43 was recorded after 3,6 and 9 days respectively. An average growth of $4.2 \mathrm{~cm}, 6.1 \mathrm{~cm}$ and $8.2 \mathrm{~cm}$ was recorded on carrot agar after 3, 6 and 9 days respectively. On Rye agar the average observed growth was $3.2 \mathrm{~cm}, 5.26 \mathrm{~cm}$ and $8.5 \mathrm{~cm}$ after 3, 6 and 9 days respectively. Rye agar and V8 juice agar offered luxuriant growth of $P$. capsici during sub culturing. As shown in figure 1 during sub culturing Rye agar gave the best results while on the other hand PARP was the least effective medium for promoting mycelial growth of the pathogen.

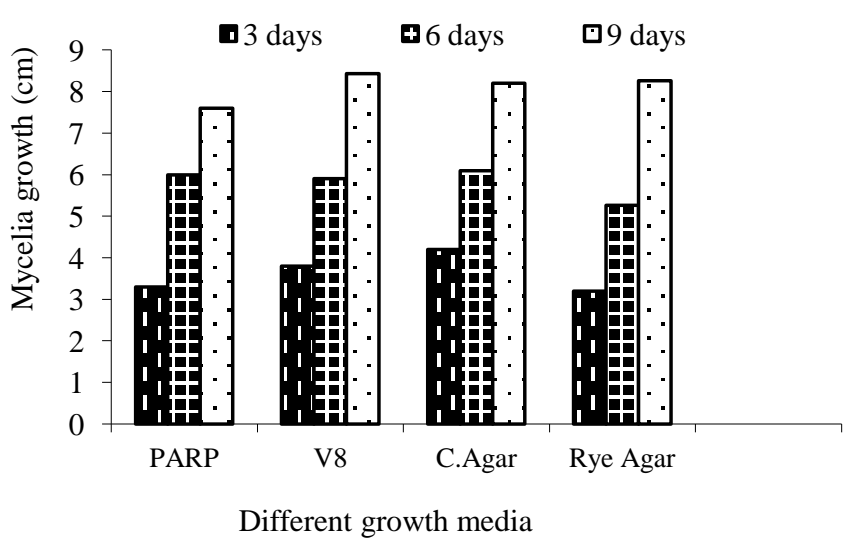

Fig. 1: Effect of different growth media on mycelial growth of $P$. capsici during sub-culturing.

\subsubsection{Statistical Analysis}

Comparison of Mycelial growth of $P$. capsici during Sub culturing on different media Table 1 and 2. 
Table 1: Analysis of variance

\begin{tabular}{lcccc}
\hline \multicolumn{1}{c}{ Source } & DF & SS & MS & F \\
\hline Replications & 2 & 1.177 & 0.5886 & 10.58 \\
Treatments & 3 & 2.988 & 0.9958 & 0.0083 \\
Error (Replication*Treatment) & 6 & 0.565 & 0.0942 & \\
Time & 2 & 115.721 & 57.8603 & 166.77 \\
Treatment*Time & 6 & 4.362 & 0.7269 & 2.10 \\
Error (Replication*Treatment*Time) & 16 & 5.551 & 0.3469 & 0.0000 \\
Total & 35 & 130.363 & & \\
\hline
\end{tabular}

Note. Grand Mean $=5.8361 ;$ CV $($ Replication*Treatment*Time $)=10.09$.

Table 2: LSD All pairwise comparisons test for treatments (Media).

\begin{tabular}{ccc}
\hline Treatment & Mean & Homogeneous groups \\
\hline Rye Agar & 6.1667 & $\mathrm{~A}$ \\
PARP & 5.4778 & $\mathrm{~B}$ \\
Carrot Agar & 5.6333 & $\mathrm{~B}$ \\
V8 & 6.0667 & $\mathrm{~A}$ \\
\hline
\end{tabular}

Note. Alpha $=0.05$; Standard Error for comparison $=0.1447$; Critical value for comparison $=0.3540$; Error term used: Replication*Treatment, Degree of Freedom $=6$. There are two groups (A and B) in which the means are not significantly different from one another.

\subsection{Evaluation of plant extracts for $\boldsymbol{P}$. capsici growth inhibition}

Out of 6 plant extracts being evaluated for their efficacy against $P$. capsici, Parthenium was found to be $100 \%$ effective followed by Kaner which was not as effective as Parthenium but it also inhibited the growth to some extent (Table 3). While other 4 plant extracts such as, Amaltas, Akk, Neem and Niazbo showed stimulatory effect on growth of $P$. capsici.

The efficacy of the plant extracts was expressed as percent inhibition of mycelial growth over control, which was calculated by using the formula of Vincent (1927) (Table 4)[14].

$$
\mathrm{I}=\frac{\mathrm{C}-\mathrm{T}}{\mathrm{C}} \times 100
$$

Where; $\mathrm{I}=$ Percent inhibition, $\mathrm{C}=$ Growth in control, $\mathrm{T}=$ Growth in treatment.

Table 3: Measurement of colony diameter in $\mathrm{mm}$ on $7^{\text {th }}$ day.

\begin{tabular}{cccccc}
\hline Treatments & \multicolumn{4}{c}{ Growth in ' $\mathbf{m m}$ ' } & Mean \\
\cline { 2 - 4 } & $\mathbf{R}_{\mathbf{1}}$ & $\mathbf{R}_{\mathbf{2}}$ & $\mathbf{R}_{\mathbf{3}}$ & $\mathbf{R}_{\mathbf{4}}$ & \\
\hline Neem & 60.5 & 59 & 57.5 & 51 & 57 \\
Niazboo & 52.5 & 46.5 & 56 & 45 & 50 \\
Kaner & 42 & 47.5 & 42.5 & 50.5 & 46 \\
Amaltas & 90 & 86.5 & 90 & 85.5 & 88 \\
Akk & 64 & 68 & 52.5 & 56 & 59 \\
Parthenium & 0 & 0 & 0 & 0 & 0 \\
Control & 58 & 56.5 & 46.5 & 52.5 & 53 \\
\hline
\end{tabular}

Note. Grand Mean $=50.589 ;$ C.V. $=8.95 ; \mathrm{LSD}=10.402 ;$ Critical $\mathrm{Q}$ value $=$ 4.597

Table 4: Inhibition percentage.

\begin{tabular}{ccc}
\hline Common Name & Botanical Name & \% Inhibition \\
\hline Parthenium & Parthenium hysterophorus & 100 \\
Neem & Azadirachta indica & -7.54 \\
Niazbo & Oscimum basilicum & 5.66 \\
Akk & Calatropis gigantea & -11.32 \\
Amaltas & Cassia fistula & -66 \\
Kaner & Nerium oleander & 13.21 \\
\hline
\end{tabular}

L. Y. Guoand, W. H. Ko (1993) evaluated Tomato agar and soybean agar against phytophthora and found both be comparable to or in some cases better than the popular V8 vegetable juice agar in supporting linear growth of $P$. cactorum,
P. capsici, P. parasitica, Pythium aphanidermatum, and Pythium splendens; sporangium production of $P$. capsici, $P$. palmivora, and Pythium splendens; and oospore formation of $P$. cactorum, $P$. parasitica, Pythium aphanidermatum and Pythium splendens [15]. These two media with readily accessible ingredients can be used to substitute for V8 juice agar in pathological and physiological studies of these two important groups of fungi in countries where V8 vegetable juice is not available or difficult to obtain. Syed Fayaz Ali Shah et al. (2013) tested Potato Dextrose Agar (PDA), Corn Meal Agar (CMA) and Water Agar (WA) for radial colony growth, sporangial production/germination and biomass production of $P$. capsici [16]. PDA proved to be the best medium in having maximum colony growth, the highest biomass production and $95 \%$ spore germination in the least possible time. Among the five different phytobiocides having tested, extracts from garlic, cabbage and peppermint retarded the mycelial growth while those from onion and radish stimulated the pathogen development. Tsopmbeng et al. (2012) found V6 juice agar (64mm) the best medium for Phytophthora as compared to V8-m juice agar $(57 \mathrm{~mm})$, onion agar $(55 \mathrm{~mm})$, V8 juice agar $(54 \mathrm{~mm})$ and potato dextrose agar $(54 \mathrm{~mm})$ [17]. Wongkaew and Sinsiri (2014) tested three plant extracts against different fungi and found effective against Phytophthora infestan [18]. Abayhne and Chauhan (2016) evaluated various plant extracts against Phytophthora infestans and found Eucalyptus highly effective against Phytophthora [19]. Jagtapa et al. (2012) tested six plant extracts and found effective against three species of Phytophthora [20]. Sarpong (2016) evaluated plants extracts against Phytopthora and Neem was found effective against Phytophthora [21]. Our results are also fortify by the findings of Bahraminejad et al. (2013), they tested 32 species of plants extracts and found all effective against Phytophthora and Phythium [22]. Our outcomes are also in line with the findings of Bahraminejad et al. (2012), their results showed that plant extracts were effective against Phytophthora drechsleri [23]. The findings of Bekepe (2012) also substantiate our discoveries; they conclude that $2 \%$ Garlic extracts was effective against Phytophthora [24]. 


\section{CONCLUSIONS}

For $P$. capsici isolation PARP is the best media but for sub culturing and purification Rye agar is performed well. Parthenium is the excellent solution for $P$. capsici management as it showed $100 \%$ results. We recommend it for all the Phytophthora diseases. Our findings of this report are very much helpful in plant protection studies.

\section{ACKNOWLEDGMENTS}

The authors acknowledge the support of Govt. of the Punjab, Agriculture Department and Director, Plant Pathology Research Institute, AARI, Faisalabad (Punjab) Pakistan, for their support and financial help.

Conflict of interest: There is no conflict of interest.

\section{REFERENCES}

1. Satour MM, Butler EE. A root and crown rot of tomato caused by Phytophthora capsici and P. parasitic. Phytopathology. 1967; 57:510-515.

2. Babadoost M. Outbreak of Phytophthora foliar blight and fruit rot in processing pumpkin field in Illinois. Plant Dis. 2000; 84:1345.

3. Tegegne F, Peters KJ, Kijora C. Cactus pear (Opuntisficusindica): a strategic crop in combating food and feed insecurity and desertification in Ti gray, northern Ethiopia. Proceedings of the Society of Nutrition Physiology. 2005; 14:60-73.

4. Abdolmaleki M, Bahraminejad S, Abassi S, Mahmodi SB. Inhibitory effect of some plant extracts on mycelial growth of Rhizoctoniasolani and Phytophthora drechsleri, sugar beet root rot agent. J Sugar Beet. 2010; 25:193-205.

5. Abdolmaleki M, Salari M, Bahraminejad S, Panjekeh N, Abassi S. Antifungal activity of cinnamon (Cinnamomumzelanicum) crude extracts against some phytopathogenic fungi. Iranian J Plant Pathol. 2008; 44:255-261.

6. Kim MJ, Mutschler MA. Late blight resistance of L. pimpinellifolium L3708: Characterization and transfer to processing tomato. Tomato Breeders Round Table, 2003. Available from: http://ce.byu.edu/cw/tomato.

7. Ambang Z, Ndongo B, Essono G, Ngoh JP, Kosma P, Chewachong GM, Sganga A. Control of leaf spot disease caused by Cercospora sp. on groundnut (Arachishypogeae) using methanolic extracts of yellow oleander (Thevatiaperuviana). Aus JCrop Sci. 2011; 5 (3):227-232.

8. Demirci F, Dolar FS. Effects of some plant materials on phytophthora blight (Phytophthora capsici L.) of pepper. Turk J AgriFor. 2006; 30:247-252.

9. Lilly VG, Barnett HL. Physiology of the Fungi, McGraw-Hill Book Co., New York, Toronto, London. 1951, pp. 22-44, 304-337, 355371.

10. Kannwischer ME, Michell DH. The influence of fungicides on the epidemiology of black shank of tobacco. Phytopathology. 1978; 68:1760-165

11. Brasier CM, Krik S. Protocols for Susceptibility Testing. Production of gametangia by Phytophthora ramorum in vitro. Myco res. 2004; 108:823-827.
12. Forbes, G. Laboratory manual for Phytophthora infestans work at CIP-Quito. 2001; CIP:1-40.

13. Sahi ST, Habib A, Ghazanfar MU, Badar A. In vitro evaluation of different fungicides and plant extracts against Botryodiplodiatheobromae, the causal agent of quick decline of mango. Pak J Phytopathol. 2012; 24(2):137-142.

14. Vincent JM. Distortion of fungal hyphae in the presence of certain inhibitors. Nature. 1927; 59 (4051):850.

15. Guo LY, Ko WH. Hormonal regulation of sexual reproduction and mating type change in heterothallic Pythium splendens. Mycol Res. 1991; 95:452-456.

16. Shah SFA, Hussain S, Shahid M, Farooq, Rauf MA, Rahman J. Molecular detection of Phytophthora Capsicifrom Chilli (Capsicum annum $\mathrm{L}$.) and its response to selected growth media and vegetable extracts. Inter J Devel Sus. 2013; 2(2): 1312-1323.

17. TsopmbengGR, FontemDA, Yamde KF. Evaluation of culture media for growth and sporulation of Phytophthora colocasiae causal agent of taro leaf blight. Inter J Bio Chem Sci. 2012; 6(4):1566-1573.

18. Wongkaew P, Sinsiri W. Effectiveness of ringworm cassia and turmeric plant extracts on growth inhibition against some important plant pathogenic fungi. Amer J Plant Sci. 2014; 5:615-626.

19. Abayhne MA, Chauhan NM,Antifungal Activity of Various Medicinal Plants against Late Blight of Potato from Ethiopia. J Scient Res Rep. 2016; 12(5):1-9.

20. Jagtapa GP, Dhavalea MC, Deya U, Evaluation of natural plant extracts, antagonists and fungicides in controlling root rot, collar rot, fruit (brown) rot and gummosis of citrus caused by Phytophthora spp. In vitro. Scient J Microb. 2012; 1(2):27-47.

21. Sarpong MT, In Vitro Evaluation of the Effect of Selected Plant Extracts on the Phytophthora Fungus Causing Disease in MD2 Variety of Pineapple in the Central Region of Ghana. EC Microbiol, 2016, pp. 623-632.

22. Bahraminejad S, Amiri R, Ghasemi S, Fathi N, Inhibitory effect of some Iranian plant species against three plant pathogenic fungi. Inter J Agri Crop Sci. 2013; 5(9):1002-1008.

23. Bahraminejad S, Abbasi S, Maassoumi SM, Tabein S, 2012 Evaluation of inhibitory effects of extracts of plants from western Iran against Phytophthora drechsleri. Aus J Crop Sci. 2012; 6(2):255-260.

24. Bekepe K, Sommartya T, Rakvidhyasastra V, Singburaudom N, Sukprasert P, Berga L, Crude Garlic Extract Effect on the Growth of Mycelia, Germination of Zoospores and Sporangia and Time of Application on the Infection of Phytophthora infestans (Mont.) de Bary of Potato under Controlled Conditions in Ethiopia. Kasetsart J (Nat. Sci.). 2006; 40:729-737.

\section{How to cite this article:}

Mohsan M, Ali S, Shahbaz MU, Saeed S, Burhan M. In vitro efficacy of different growth media and crude plant extracts against mycelia growth of Phytophthora capsici. J App Biol Biotech 2017; 5 (04): 043-047. 